\title{
Aspectos da germinação de sementes de assa-peixe (Vernonia polyanthes Less.)
}

\author{
Aspects of the germination of assa-peixe seeds (Vernonia polyanthes Less.)
}

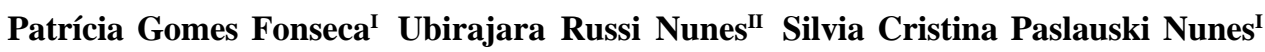

\section{RESUMO}

\begin{abstract}
O objetivo do presente trabalho foi avaliar o efeito da temperatura e luz na germinação de sementes de assapeixe (Vernonia polyanthes Less.). Para tanto foram testadas seis temperaturas constantes $\left(15,20,25,30,35\right.$ e $\left.40^{\circ} \mathrm{C}\right) e$ quatro combinações de temperaturas alternadas (15-20, $15-$ 25, 20-30 e 20-35 $\mathrm{C}$ ) na presença e ausência de luz, a qual foi fornecida durante os períodos de temperaturas mais altas, quando avaliada a alternância. As variáveis avaliadas foram: teor de água, germinação e vigor (primeira contagem e velocidade de germinação). O delineamento experimental adotado foi o inteiramente casualizado e os resultados foram submetidos à análise da variância, com as médias comparadas pelo teste de Tukey a 5\% de probabilidade. Sementes da espécie V. polyanthes são fotoblásticas preferenciais, com germinação favorecida pela presença de luz, mas as maiores porcentagens de germinação e níveis de vigor dessas sementes foram obtidas em temperaturas de $25^{\circ} \mathrm{C}$ constante e de $15-25^{\circ} \mathrm{C}$ alternada, na presença de luz.
\end{abstract}

Palavras-chave: vigor, Asteraceae, fotoblástica.

\section{ABSTRACT}

The objective of this research was to evaluate the effect of temperature and light on germination of Vernonia polyanthes Less. seeds. Therefore were tested six constant temperatures $\left(15,20,25,30,35\right.$ and $\left.40^{\circ} \mathrm{C}\right)$, and four combinations of alternating temperatures (15-20, 15-25, 20 30 and $20-35^{\circ} \mathrm{C}$ ) in the presence and absence, which was provided during periods of higher temperatures, when evaluating the rotation. The variables evaluated were: degree of moisture, germination and vigor (first count of germination and speed of germination). The completely random design was used and the results were submitted to analysis of variance with means compared by Tukey test at 5\% probability. Seeds of the Vernonia polyanthes species are preferential photoblastic with germination favored in the presence of light. The highest percentage of germination and seed vigor levels of the seeds of V. polyanthes were obtained in temperatures of $25^{\circ} \mathrm{C}$ constant and alternating $15-25^{\circ} \mathrm{C}$ in the presence of light.

Key words: vigor, Asteraceae, fothoblastic.

\section{INTRODUÇÃO}

Vernonia polyanthes Less., da família Asteraceae, popularmente conhecida como assa-peixe ou assa-peixe branco é uma planta silvestre comum nos cerrados de Minas Gerais, São Paulo, Mato Grosso e Goiás (ALVES \& NEVES, 2003), que tem potencial apícola e propriedades medicinais (MATTOS et al., 2005), entretanto, ainda são escassas as informações sobre a resposta fisiológica de suas sementes à luz e a temperatura.

A presença ou ausência de luz, combinada com diferentes temperaturas são fatores ambientais dos mais comuns como agentes desencadeadores da germinação, podendo haver interação desses fatores, em temperatura constante ou alternada (SILVA et al., 2002). SCALON et al. (2007) mencionaram que há uma temperatura ótima na qual se observa o máximo de

IUniversidade Federal dos Vales do Jequitinhonha e Mucuri (UFVJM), Departamento de Agronomia, 39100-000, Diamantina, MG, Brasil.

IIUniversidade Federal de Santa Maria (UFSM), Departamento de Fitotecnia, Setor de Sementes, Campus Universitário, 97105900, Santa Maria, RS, Brasil. E-mail: russinunes@yahoo.com.br. Autor para correspondência. 
germinação em menor intervalo de tempo e os efeitos da temperatura na germinação de sementes podem ser avaliados pelas mudanças ocasionadas na porcentagem, velocidade e frequência relativa de germinação, durante o período de incubação.

Em relação à luz, as espécies podem ser classificadas em fotoblásticas positivas, ou seja, aquelas cujas sementes necessitam de luz para germinar; fotoblásticas negativas, que germinam melhor na ausência de luz ou fotoblásticas neutras que são insensíveis à luz. Estas respostas estão relacionadas ao pigmento receptor denominado fitocromo, que é o responsável pela captação dos sinais luminosos, podendo ou não desencadear a germinação das sementes (ARAÚJO-NETO et al., 2002).

Alguns trabalhos relacionados a avaliação da germinação das sementes de espécies pertencentes à família Asteraceae foram desenvolvidos, a exemplo de Bacharis trimera, Eupatorium laevigatum, Mikania cordifolia, Senecio oxyphyllus e Trixis praestens (FERREIRA et al., 2001), bem como Eremanthus incanus, E. elaeagnus e E.glomerulatus, (VELTEN \& GARCIA, 2005), cuja resposta à luz dependeu da temperatura à qual as sementes foram expostas.

Buscando compreender aspectos relacionados à germinação, este trabalho teve como objetivo avaliar o efeito da temperatura e luz na germinação de sementes de $V$. polyanthes.

\section{MATERIAL E MÉTODOS}

As sementes de V. polyanthes foram coletadas manualmente em uma área nativa de $500 \mathrm{~m}^{2}$ de extensão no Campus II ( $18^{\circ} 9^{\prime}$ 'S e $43^{\circ} 22^{\prime} \mathrm{W}$, altitude média de $1.296 \mathrm{~m}$, temperatura média anual de $18,1^{\circ} \mathrm{C}$ ) da Universidade Federal dos Vales do Jequitinhonha e Mucuri (UFVJM), em Diamantina - MG, de 1 de setembro a 30 de dezembro de 2006. Para eliminação das impurezas utilizaram-se peneiras manuais e a secagem das sementes foi realizada à sombra; em seguida, no Laboratório de Análise de Sementes da UFVJM as sementes foram caracterizadas quanto: determinação do teor de água (\%), germinação e vigor (primeira contagem e velocidade de germinação).

Para a determinação do teor de água utilizouse o método da estufa a $105 \pm 3^{\circ} \mathrm{C}$ por 24 horas, sendo a porcentagem de água calculada com base na relação entre o peso úmido e o seco, utilizando-se estufa e balança analítica com precisão de $0,0001 \mathrm{~g}$, conforme as Regras para Análise de Sementes (BRASIL, 2009).

Os testes de germinação foram realizados em germinadores do tipo Biochemical Oxigen Demand
(B.O.D.), em quatro repetições de 25 sementes por tratamento com luz artificial no interior da câmara

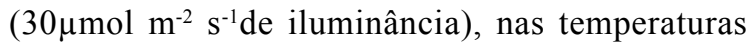
constantes de $15,20,25,30,35$ e $40^{\circ} \mathrm{C}$, na presença e ausência de luz, bem como nas combinações de temperaturas alternadas de $15-20,15-25,20-30$ e 20 $35^{\circ} \mathrm{C}$ (diurno/noturno), em fotoperíodo de oito horas, sendo que nas temperaturas mais elevadas utilizou-se o período de luz. A simulação da condição escuro (ausência de luz) foi realizada em caixas gerbox, cobertas com papel alumínio e mantidas em saco de polietileno.

O teste de germinação foi conduzido em caixas de plástico do tipo gerbox, sobre papel germitest umedecido com quantidade de água destilada equivalente a duas vezes a massa do papel seco (BRASIL, 2009); as caixas foram envoltas em saco de polietileno transparente para evitar a perda de água para o meio. As contagens das plântulas foram realizadas no $4^{\circ}$ dia para a primeira contagem (vigor) e no $8^{\circ}$ dia para a contagem final do teste de germinação. A emergência da raiz primária, numa extensão de mais da metade do comprimento da semente foi o critério usada para caracterizar a germinação (FERREIRA et al., 2001).

A velocidade de germinação foi avaliada pela contagem diária das sementes (protrusão da raiz primária), sendo calculado o índice de velocidade através da fórmula proposta por MAGUIRE (1962), somente para o teste conduzido em presença de luz.

O delineamento experimental foi inteiramente casualizado, com quatro repetições, em esquema fatorial $6 \times 2$ e 4x2 (temperaturas x condição de luz). Os dados foram submetidos à análise de variância e as médias comparadas entre si pelo teste de Tukey a 5\% de probabilidade. Os dados em porcentagem foram transformados em arco-seno $\sqrt{\% / 100}$, conforme sugerido por SANTANA \& RANAL (2004); o programa estatístico utilizado foi o software SISVAR (FERREIRA, 2003).

\section{RESULTADOS E DISCUSSÃO}

O teor de água inicial das sementes de $\boldsymbol{V}$. polyanthes, que estavam em processo de dispersão foi de $10,51 \%$. Na primeira contagem de germinação (Tabela 1), na presença de luz, os maiores percentuais alcançados foram a 20 e $25^{\circ} \mathrm{C}(24$ e $33 \%$, respectivamente), com valores não diferindo entre si estatisticamente. Para a germinação (Tabela 1), o maior percentual observado foi a $25^{\circ} \mathrm{C}(34 \%)$ e, os menores percentuais foram computados a 15 e $35^{\circ} \mathrm{C}$, não diferindo significativamente.

Os percentuais na primeira contagem e germinação na ausência de luz (Tabela 1) foram inferiores aos obtidos na presença, sendo os maiores 
Tabela 1 - Primeira contagem da germinação, germinação e índice de velocidade da germinação de sementes de V. polyanthes em função da luz e temperaturas constantes.

\begin{tabular}{|c|c|c|c|c|c|c|}
\hline Condição de luz & $15^{\circ} \mathrm{C}$ & $20^{\circ} \mathrm{C}$ & $25^{\circ} \mathrm{C}$ & $30^{\circ} \mathrm{C}$ & $35^{\circ} \mathrm{C}$ & $40^{\circ} \mathrm{C}$ \\
\hline Presença & $8 \mathrm{Ca}$ & $24 \mathrm{ABa}$ & $33 \mathrm{Aa}$ & $20 \mathrm{Ba}$ & $6 \mathrm{Ca}$ & $0 \mathrm{Da}$ \\
\hline Ausência & $4 \mathrm{Bb}$ & $14 \mathrm{Ab}$ & $18 \mathrm{Ab}$ & $14 \mathrm{Ab}$ & $1 \mathrm{BCb}$ & $0 \mathrm{Ca}$ \\
\hline CV (\%) & 20,87 & & & & & \\
\hline Condição de luz & $15^{\circ} \mathrm{C}$ & $20^{\circ} \mathrm{C}$ & $25^{\circ} \mathrm{C}$ & $30^{\circ} \mathrm{C}$ & $35^{\circ} \mathrm{C}$ & $40^{\circ} \mathrm{C}$ \\
\hline Presença & $10 \mathrm{Ca}$ & $25 \mathrm{Ba}$ & $34 \mathrm{Aa}$ & $22 \mathrm{Ba}$ & $6 \mathrm{Ca}$ & $0 \mathrm{Da}$ \\
\hline Ausência & $6 \mathrm{Bb}$ & $18 \mathrm{Ab}$ & $21 \mathrm{Ab}$ & $20 \mathrm{Aa}$ & $3 \mathrm{Bb}$ & $0 \mathrm{Ca}$ \\
\hline CV (\%) & 13,86 & & & & & \\
\hline Condição de luz & $15^{\circ} \mathrm{C}$ & $20^{\circ} \mathrm{C}$ & $25^{\circ} \mathrm{C}$ & $30^{\circ} \mathrm{C}$ & $35^{\circ} \mathrm{C}$ & $40^{\circ} \mathrm{C}$ \\
\hline Presença & $0,79 \mathrm{DE}$ & $2,83 \mathrm{C}$ & $7,59 \mathrm{~A}$ & $4,00 \mathrm{~B}$ & $1,04 \mathrm{D}$ & $0 \mathrm{E}$ \\
\hline CV (\%) & 14,36 & & & & & \\
\hline
\end{tabular}

Médias seguidas pela mesma letra, maiúscula na linha e minúscula na coluna, em cada variável, não diferem entre si a $5 \%$, pelo teste de Tukey.

valores de germinação iguais entre si para as temperaturas de 20,25 e $30^{\circ} \mathrm{C}$ e extremamente baixas nas temperaturas de 15 e $35^{\circ} \mathrm{C}$, enquanto na presença e na ausência de luz, na temperatura de $40^{\circ} \mathrm{C}$ ocorreu perda da viabilidade das sementes (Tabela 1).

Em relação ao índice de velocidade de germinação apenas na presença de luz (Tabela 1) o maior valor obtido foi a $25^{\circ} \mathrm{C}(7,59)$, demonstrando que esta temperatura favoreceu o vigor das sementes de $\boldsymbol{V}$. polyanthes, as quais germinaram em maior velocidade.

Nas faixas de temperaturas alternadas, em presença de luz, os maiores percentuais para primeira contagem e germinação (Tabela 2) foram observados a $15-25$ e $20-30^{\circ} \mathrm{C}$ que não diferiram entre si. Os maiores valores observados, para ambos os testes foram obtidos nas faixas de temperaturas de $15-20$ e $20-35^{\circ} \mathrm{C}$, que foram estatisticamente iguais entre si na presença de luz; nas temperaturas alternantes testadas, a maior porcentagem de germinação obtida foi a $15-25^{\circ} \mathrm{C}(32 \%)$ na presença de luz.

$\mathrm{Na}$ ausência de luz obteve-se os menores valores para o teste de primeira contagem e germinação (Tabela 2), comparados aos obtidos na presença de luz, enquanto os maiores valores, para vigor foram observados nas faixas de temperatura de 15-25 (18\%) e $20-30^{\circ} \mathrm{C}(13 \%)$, que não diferiram entre si. Para a germinação, a maior percentagem obtida foi na faixa de temperatura de $15-25^{\circ} \mathrm{C}(24 \%)$; em ambos os testes os menores valores percentuais foram obtidos na faixa de temperatura de $20-35^{\circ} \mathrm{C}$.

Para o índice de velocidade de germinação, avaliado apenas na presença de luz (Tabela 2), os maiores valores registrados foram nas faixas de temperatura de $15-25$ e $20-30^{\circ} \mathrm{C}$, que foram iguais entre si $(3,7)$, enquanto o menor valor $(1,23)$ registrado foi na faixa de temperatura de $15-20^{\circ} \mathrm{C}$.

A germinação das sementes de $\boldsymbol{V}$. polyanthes não foi restrita à presença de luz, uma vez que também ocorreu no escuro contínuo, apesar de significativamente menor, entretanto, a germinação foi maior na presença de luz a $25^{\circ} \mathrm{C}$ do que no escuro contínuo. Seguindo o critério adotado por KLEIN \& FELIPE (1991), as sementes desta espécie respondem como fotoblásticas preferenciais pelo fato de ter ocorrido germinação no escuro, mas preferencialmente esta foi favorecida na presença de luz. Esses resultados concordam com FERREIRA et al. (2001) que estudaram a germinação de Asteraceae nativas e classificaram as espécies Eclipta alba, Elephantopus mollis, Senecio oxyphyllus, Senecio selloi e Vernonia nudiflora como fotoblásticas positivas preferenciais, pois os percentuais de germinação foram significativamente mais altos na presença luz, mas sem atingirem mais que o dobro do regime do escuro.

Mesmo na temperatura mais eficiente para promover a germinação $\left(25^{\circ} \mathrm{C}\right)$, com luz e temperaturas constantes, esta foi inferior a 50\% (34\%), demonstrando baixa germinação das sementes nativas de $\boldsymbol{V}$. polyanthes. Resultados semelhantes foram obtidos por FERREIRA et al. (2001) que também registraram baixo percentual de germinação para as sementes de Bacharis trimera (abaixo de 20\%); Eupatorium Iaevigatum (30\%); Mikania cordifolia (30\%); Senecio oxyphyllus (40\%) e Trixis praestens (20\%), da família Asteraceae. 
Tabela 2 - Primeira contagem da germinação, germinação e índice de velocidade de germinação de sementes de $\boldsymbol{V}$. polyanthes submetidas a temperaturas alternadas, sob fotoperíodo de oito horas.

\begin{tabular}{|c|c|c|c|c|}
\hline Condição de luz & $15-20^{\circ} \mathrm{C}$ & $15-25^{\circ} \mathrm{C}$ & $20-30^{\circ} \mathrm{C}$ & $20-35^{\circ} \mathrm{C}$ \\
\hline Presença & $15 \mathrm{Ba}$ & $30 \mathrm{Aa}$ & $29 \mathrm{Aa}$ & $16 \mathrm{Ba}$ \\
\hline Ausência & $11 \mathrm{Ba}$ & $18 \mathrm{Ab}$ & $13 \mathrm{ABb}$ & $5 \mathrm{Cb}$ \\
\hline CV $(\%)$ & 11,11 & & & \\
\hline Condição de luz & $15-20^{\circ} \mathrm{C}$ & $15-25^{\circ} \mathrm{C}$ & $20-30^{\circ} \mathrm{C}$ & $20-35^{\circ} \mathrm{C}$ \\
\hline Presença & $17 \mathrm{Ba}$ & $32 \mathrm{Aa}$ & $29 \mathrm{Aa}$ & $19 \mathrm{Ba}$ \\
\hline Ausência & $13 \mathrm{BCa}$ & $24 \mathrm{Ab}$ & $17 \mathrm{Bb}$ & $8 \mathrm{Cb}$ \\
\hline \multirow[t]{2}{*}{ CV (\%) } & 9,71 & & & \\
\hline & $15-20^{\circ} \mathrm{C}$ & $\begin{array}{l}- \text { Indice de } \\
15-25^{\circ} \mathrm{C}\end{array}$ & $\begin{array}{l}\text { erminaçã } \\
20-30^{\circ} \mathrm{C}\end{array}$ & $20-35^{\circ} \mathrm{C}$ \\
\hline Presença & $1,23 \mathrm{~B}$ & $3,7 \mathrm{~A}$ & $3,7 \mathrm{~A}$ & $1,61 \mathrm{~B}$ \\
\hline $\mathrm{CV}(\%)$ & 12,79 & & & \\
\hline
\end{tabular}

Médias seguidas pela mesma letra, maiúscula na linha e minúscula na coluna, em cada variável, não diferem entre si a $5 \%$, pelo teste de Tukey.

Embora tenha ocorrido germinação a 15 e a $35^{\circ} \mathrm{C}$, também constatado por VELTEN \& GARCIA (2005) em estudo com sementes de Eremanthus incanus (Asteraceae), nestas temperaturas o vigor das sementes foi menor, pelo fato de germinarem em menor velocidade. De acordo com CARVALHO \& NAKAGAWA (2000), temperaturas inferiores ou superiores à ótima tendem a reduzir a velocidade do processo germinativo, expondo as plântulas por maior período a fatores adversos, podendo levar à redução do processo germinativo.

Não foi observada germinação das sementes quando submetidas a $40^{\circ} \mathrm{C}$ na temperatura e luz constantes, tendo sido observado a perda da viabilidade das mesmas, evidenciada através do extravasamento de substâncias, que causaram odor desagradável no substrato. Resultados semelhantes foram obtidos por VELTEN \& GARCIA (2005) que não verificaram germinação na temperatura de $40^{\circ} \mathrm{C}$, para sementes de Eremanthus incanus, E. elaeagnus e $\boldsymbol{E}$. glomerulatus, da família Asteraceae. ZHAO et al. (1994) relataram que em sementes de algumas espécies, a aceleração da atividade respiratória, devido a elevação da temperatura pode causar redução ou até mesmo inibição do número total de sementes germinadas, que está de acordo com resultados obtidos no presente trabalho.

As sementes de muitas espécies, principalmente as menos domesticadas requerem flutuação diária de temperatura para germinar adequadamente (SILVA et al., 2002), o que foi observado no presente estudo, pois obteve-se $32 \%$ de germinação utilizando-se alternância de temperatura de $15-25^{\circ} \mathrm{C}$, sendo que valor semelhante também foi obtido quando se usou temperatura constante de $25^{\circ} \mathrm{C}(34 \%)$. Ao avaliar a germinação de sementes de Eremanthus (Asteraceae) VELTEN \& GARCIA(2005) verificaram que os tratamentos de temperatura alternada não promoveram a germinação de $\boldsymbol{E}$. elaeagnus e $\boldsymbol{E}$. glomerulatus. SILVA et al. (2002) mencionaram que para algumas espécies, a germinação das sementes é promovida quando submetidas à temperatura constante, outras necessitam de temperatura alternada, havendo ainda espécies que germinam em temperatura constante ou alternada.

\section{CONCLUSÃO}

As sementes da espécie Vernonia polyanthes são fotoblásticas preferenciais, cuja germinação é favorecida na presença de luz. As maiores porcentagens de germinação e níveis de vigor de sementes são obtidas em temperaturas de $25^{\circ} \mathrm{C}$ constante e de $15-25^{\circ} \mathrm{C}$ alternada, na presença de luz.

\section{REFERÊNCIAS}

ALVES, V.F.G.; NEVES, L.J. Anatomia foliar de Vernonia polyanthes Less. (Asteraceae). Revista Universidade Rural, Série Ciências da Vida, Rio de Janeiro, v.22, n.2, p.1-8, 2003.

ARAÚJO-NETO, J.C.A. et al. Temperaturas cardeais e efeito da luz na germinação de sementes de mutamba. Revista Brasileira de Engenharia Agrícola e Ambiental, Campina Grande, v.6, n.3, p.460-465, 2002. Disponível em: <http:// www.scielo.br/pdf/rbeaa/v6n3/v6n3a13.pdf $>$. Acesso em: 01 set. 2011. doi: 10.1590/S1415-43662002000300013. 
BRASIL. Ministério da Agricultura, Pecuária e Abastecimento. Regras para análise de sementes. Secretaria de Defesa Agropecuária. Brasília: MAPA/ACS, 2009. 395p.

CARVALHO, N.M.; NAKAGAWA, J. Sementes: ciência, tecnologia e produção. Jaboticabal: FUNEP, 2000. 588p.

FERREIRA, A.G. et al. Germinação de sementes de Asteraceae nativas do Rio Grande do Sul, Brasil. Acta Botanica Brasilica, São Paulo, v.15, n.2, p.231-242, 2001. Disponível em: <http:/ /www.scielo.br/scielo.php?script $=$ sci_pdf\&pid=S0102$33062001000200009 \& \operatorname{lng}=\mathrm{pt} \& \mathrm{nrm}=\mathrm{iso} \& \operatorname{tn} \mathrm{ln}=\mathrm{pt}>$. Acesso em: 01 set. 2011. doi: 10.1590/S0102-33062001000200008.

FERREIRA, D.F. Programa de análises estatísticas (Statistical Analysis Software) e planejamento de experimentos. SISVAR 5.0 (Build 67). 2003. Disponível em: $<$ http://www.dex.ufla.br/ danielff/softwares.htm $>$. Acesso em: 03 maio, 2008

KLEIN, A.; FELIPE, G.M. Efeito da luz na germinação de sementes de ervas invasoras. Pesquisa Agropecuária Brasileira, Brasília, v.26, n.7, p.955-966, 1991.

MAGUIRE, J.D. Speed of germination-aid in selection and evaluation for seedling emergence and vigor. Crop Science, Madison, v.2, n.1, p.176-177, 1962

MATTOS, S. et al. Estudos parciais dos metabólicos secundários de flores e folhas da Vernonia sp. Less. (Asteraceae). In:
CONGRESSO DE INICIAÇÃO CIENTÍFICA DO CENTRO UNIVERSITÁRIO LUTERANO DE PALMAS, 4., 2005, Palmas. Anais... Palmas: CEULP/ULBRA, 2005. p.455-457.

SANTANA, D.G.; RANAL, M.A. Análise estatística na germinação. Brasília: Universidade de Brasília, 2004. 248p.

SCALON, S.P.Q. et al. Temperatura, luz e substrato na germinação de sementes de cipó-mil-homens (Aristolochia triangulares Cham. Et. Schl.). Revista Brasileira de Plantas Medicinais, Botucatu, v.9, n.4, p.32-38, 2007.

SILVA, L.M.M. et al. Efeito da luz e da temperatura na germinação de sementes de aroeira (Myracrodruon urundeuva Allemão). Revista Árvore, Viçosa, v.26, n.6, p.691-697, 2002. Disponível em: <http://www.scielo.br/pdf/rarv/v26n6/ a06v26n6.pdf>. Acesso em: 01 set. 2011. doi: 10.1590/S010067622002000600006 .

VELTEN, S.B.; GARCIA, Q.S. Efeitos da luz e da temperatura na germinação de sementes de Eremanthus (Asteraceae), ocorrentes na Serra do Cipó, MG, Brasil. Acta Botanica Brasilica, São Paulo, v.19, n.4, p.753-761, 2005. Disponível em: <http:// www.scielo.br/scielo.php? script $=$ sci arttext\&pid $=\mathrm{S} 0102$ $33062005000400010 \& \operatorname{lng}=\mathrm{pt} \& \mathrm{nrm}=\mathrm{iso} \& \mathrm{t} \operatorname{lng}=\mathrm{pt}>$. Acesso em: 01 set. 2011. doi: 10.1590/S0102-33062005000400009.

ZHAO, Y.T. et al. Relationship between physical characters, chemical composition, germination and cold-tolerance in soybean. Chinese Journal of Botany, China, v.6, n.1, p.6063, 1994. 